\title{
LAMOTRIGINE INDUCED DRESS SYNDROME
}

\author{
SAURABH AGARWAL ${ }^{1}$, BALAJI 0 ${ }^{1}$, AMITA PRIYA D ${ }^{1}$, MOHAN A ${ }^{1 *}$, MEENA K
}

${ }^{1}$ Department of Pharmacology, Kasturba Medical College, Manipal University, Manipal, Karnataka, India. ${ }^{2}$ Department of Internal Medicine, Kasturba Medical College, Manipal University, Manipal, Karnataka, India. Email: navin903@gmail.com

Received: 03 April 2017, Revised and Accepted: 22 May 2017

\section{ABSTRACT}

Drug rash with eosinophilia and systemic symptoms (DRESS) syndrome, is a type of hypersensitivity reaction, mainly due to antiepileptic drugs. Lamotrigine is a newer broad-spectrum antiepileptic that can be used in both children and adults. Lamotrigine-induced DRESS syndrome is a rare case with incidence of $1 / 1000$ to $1 / 10000$. This syndrome manifests as rash, fever, tender lymphadenopathies, hepatitis, and eosinophilia. This case highlights the need for early diagnosis and treatment of such a rare and life-threatening event because early detection of the condition leads to early recovery of the patient. Further re-exposure to the drug should be avoided.

Keywords: Liver toxicity, Skin rash, Eosinophilia, Adverse drug reaction.

(c) 2017 The Authors. Published by Innovare Academic Sciences Pvt Ltd. This is an open access article under the CC BY license (http://creativecommons. org/licenses/by/4. 0/) DOI: http://dx.doi.org/10.22159/ajpcr.2017.v10i9.18876

\section{INTRODUCTION}

Drug reaction with eosinophilia and systemic symptoms (DRESS) syndrome, a type of hypersensitivity reaction, is a severe idiosyncratic reaction to drugs. Many drugs are implicated in causing DRESS which includes antiepileptics, and dapsone. Lamotrigine is a broad spectrum newer antiepileptic used for both children and adults. Common side effects include dizziness, ataxia, and diplopia but lesser known side effect is DRESS syndrome with incidence $1 / 1000$ to $1 / 10000$ exposures [1]. Here, we report a case of lamotrigine-induced DRESS syndrome.

\section{CASE REPORT}

Informed consent was taken from the patient. A 22-year-old female came with complaints of itchy red lesions all over the body for 5 days and fever for 1 week. The patient was a known case of epilepsy for 8 years and was on tablet levetiracetam for 1 year. The patient was started on lamotrigine 1 month back along with levetiracetam. Fever was a mild grade in nature and rashes had started locally a week back and became widespread all over the body and hand after 3 days. Skin examination revealed focal and erythematous macular rash on face, trunk, and upper hands. No other systemic complaints were noticed. Vitals were stable, and another system examination was normal. Laboratory investigations revealed elevated liver enzymes with elevated eosinophil count and erythrocyte sedimentation rate (Table 1). Other laboratory investigations were normal. The drug lamotrigine was stopped, and patient was treated with derma dew lotion local application 1-0-0, saran lotion for local application 1-0-0, paracetamol $650 \mathrm{mg}$, tablet

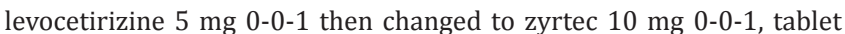
atarax $25 \mathrm{mg}$ 0-0-1, syrup zincovit 0-0-1 2 tsp, lactihusk powder 0-0-1 sos, tab levipil $750 \mathrm{~m} \mathrm{1-0-1}$, and injection avil 2 cc im sos. Treatment was continued for 4 days and epilepsy only levetiracetam was given. The patient showed improvement in condition and was discharged on the $5^{\text {th }}$ day with medications and was asked to review after 1 month or earlier if any symptoms reappear.

\section{DISCUSSION}

DRESS syndrome is caused by drugs such as phenobarbital, phenytoin, lamotrigine, carbamazepine, minocycline, and dapsone. Furthermore, may be caused by human herpes virus-8. Cases of DRESS syndrome have been reported with clinical features appearing 3-4 weeks after the administration of lamotrigine. This corresponds to the latency period commonly reported in the literature. The interval between first drug exposure and symptoms is usually 2-4 weeks but has been reported in individuals receiving anticonvulsants for 3 months [2]. Incidence of DRESS syndrome is estimated to be $1 / 1,000-1 / 10,000$ exposures. Lamotrigine-induced DRESS syndrome is very rare. This syndrome manifests as rash, fever, tender lymphadenopathies, hepatitis, and eosinophilia. DRESS syndrome is a potentially life-threatening multisystem adverse drug reaction, and accidental re-exposure and drug provocation tests must be avoided. Patients, their relatives, and treating physicians must be well informed about the causal drug. The incidence of DRESS syndrome is higher among first-degree relatives, it often mimics systemic infection, and the latency period may be too long to suspect a causal relationship with the administration of drugs. The presence of the two criteria, as given by Bocquet et al., has high sensitivity (>95\%) to diagnose DRESS. Proposed mechanism for lamotrigine causing DRESS includes hypersensitivity reaction to an aromatic ring containing antiepileptic drugs via immune activation. Other proposed mechanisms include formation of antibody and T-cell immune effectors. It is also said that levels of epoxide hydroxylase enzyme in the liver are found to be very low in patients who develop DRESS, and this leads to decreased elimination of toxic arene oxide metabolite of lamotrigine [3]

In our patient, there was elevated liver enzymes and eosinophilia with a fever which satisfied the criteria to diagnose DRESS. It was similar to the previous cases published in literature where it occurred after 3 weeks of starting lamotrigine and resolved on stopping the drug. All other drugs causing DRESS were ruled, and other skin disorders were also ruled out. Causality assessment was done using Naranjo's scale [4], and a probable causal relationship was ascribed. Adverse drug reaction was found to be moderately severe and not preventable as per Hartwig's severity [5] and Thornton's preventability scale [6].

Table 1: Laboratory investigations after lamotrigine therapy

\begin{tabular}{lll}
\hline Test done & $\mathbf{2 8 - 1 2 - 2 0 1 6}$ & $\mathbf{3 1 - 1 2 - 2 0 1 5}$ \\
\hline ALT (IU/L) & 42 & 115 \\
ALP (U/L) & 115 & 209 \\
AST (IU/L) & 52 & 73 \\
ESR (mm/hr) & 22 & 6 \\
Eosinophil (\%) & 8 & 13 \\
\hline
\end{tabular}

ALT: Alanine transaminase, ALP: Alkaline phosphatase, AST: Aspartate aminotransferase, ESR: Erythrocyte sedimentation rate 


\section{CONCLUSION}

This case highlights the need for early diagnosis and treatment of such a rare and life-threatening event because early detection of the condition leads to early recovery of the patient. Further re-exposure of the drug should be avoided.

\section{REFERENCES}

1. Fiszenson-Albala F, Auzerie V, Mahe E, Farinotti R, Durand-Stocco C, Crickx B, et al. A 6-month prospective survey of cutaneous drug reactions in a hospital setting. Br J Dermatol 2003;149(1):1018-22.
2. Silverman AK, Fairley J, Wong RC. Cutaneous and immunologic reactions to phenytoin. J Am Acad Dermatol 1988;18:721-41.

3. Naveen KN, Ravindra MS, Pai VV, Rai V, Athanikar SB, Girish M. Lamotrigine induced DRESS syndrome. Indian J Pharmacol 2012;44(6):798-800.

4. Naranjo CA, Busto U, Sellers EM, Sandor P, Ruiz I, Roberts EA, et al. A method for estimating the probability of adverse drug reactions. Clin Pharmacol Ther 1981;30(2):239-45.

5. Hartwig SC, Siegel J, Schneider PJ Preventability and severity assessment in reporting adverse drug reactions. Am J Hosp Pharm 1992;49(9):2229-32.

6. Schumock GT, Thornton JP. Focusing on the preventability of adverse drug reactions. Hosp Pharm 1992;27(6):538. 